\title{
Erratum:
}

\section{Erratum to: Determination of cut-off time of accelerated aging test under temperature stress for LED lamps}

\author{
Jian $\mathrm{HAO}^{1,2}$, Lei JING ${ }^{2}$, Hong-liang $\mathrm{KE}^{1,2}$, Yao WANG ${ }^{1,2}$, Qun $\mathrm{GAO}^{2}$, \\ Xiao-xun $\mathrm{WANG}^{1,2}$, Qiang SUN ${ }^{\dagger 2}$, Zhi-jun $\mathrm{XU}^{2}$ \\ ( ${ }^{1}$ University of Chinese Academy of Sciences, Beijing 100049, China) \\ ( ${ }^{2}$ Opto-Electronics Technology Center, Changchun Institute of Optics, Fine Mechanics and Physics, \\ Chinese Academy of Sciences, Changchun 130033, China) \\ †E-mail: sunq@ciomp.ac.cn
}

https://doi.org/10.1631/FITEE.15e0483

Erratum to: Front. Inform. Technol. Electron. Eng., 2017 18(8):1197-1204 https://doi.org/10.1631/FITEE.1500483

In the original version of this article, the second affiliation should be removed, and the correct affiliations are as given above.
In the original version of this article, the ORCID for Jian HAO is incorrect. The correct one should be http://orcid.org/0000-0002-2419-2508.

* Corresponding author

(ib) ORCID: Jian HAO, http://orcid.org/0000-0002-2419-2508

(C) Zhejiang University and Springer-Verlag GmbH Germany 2017 